\title{
The evaluation of healing effect of low- level laser treatment following gingivectomy
}

\author{
Marwa Madi ${ }^{1 *}$ and Maha M. Mahmoud ${ }^{2}$
}

\begin{abstract}
Background: Lasers have been investigated as an alternative or adjunctive tool to conventional procedures commonly used in periodontology. The application of low-level laser therapy (LLLT) in dentistry was proposed to provide minimally invasive and painless treatment as well as increasing the comfort for the patient following surgery. Thus, the purpose of the current study was to evaluate the effect of LLLT on healing following gingivectomy.
\end{abstract}

Methods: Twenty patients with inflammatory gingival enlargement on their maxillary or mandibular anterior region were included in this study. Patients were divided randomly into two groups (test group consist of ten patients) after gingivectomy a diode laser $(660 \mathrm{~nm})$ was applied to the wound area immediately post-surgery, 3 and 5 days post-surgery. The control group (ten patients) did not receive laser irradiation. Healing was evaluated clinically using healing score and visual analogue scale (VAS).

Results: The laser-treated group had significant improvement regarding the healing score at 5, 7, and 14 days p.s., and significant improvement in visual analogue scale (VAS) score was observed at day 3, 5, and 7 p.s., than the control group.

Conclusion: LLLT can be used as an effective adjunctive treatment following gingivectomy procedure to promote healing and decrease patients' discomfort.

Keywords: Gingivectomy, Low-level laser, Healing

\section{Background}

More than 40 years, lasers were considered as adjunctive therapy to conventional procedures frequently used in periodontology. Many lasers such as $\mathrm{CO}_{2}$, Er:YAG, and diode have been used for resective surgeries due to their rapid and hemostasis effect [10, 22, 38, 44]. Also, they have been used for non-surgical applications as sulcular debridement of pockets [3] and the laser-assisted new attachment procedure (LANAP) [37].

Although solid lasers, such as neodymium yttrium aluminum garnet (Nd: YAG) and Er:YAG, can be

\footnotetext{
*Correspondence: mimadi@iau.edu.sa

'Preventive Dental Sciences Department, Periodontology Division, Imam Abdulrahman Bin Faisal University, Dammam, Saudi Arabia

Full list of author information is available at the end of the article
}

utilized for hard and soft tissue applications, the unpredictable penetration depth and energy density inside the tissues have raised concerns. Alternatively, low-level laser therapy (LLLT) is indicated for a wide variety of procedures in dental practice based on the comfort, efficiency, and decreased cost than hard lasers $[5,35,40$, 43].

The extensive use of LLLT in dentistry depends on the appraisals of patient preferring superficially invasive and painless technique as well as increasing his comfort following surgery $[25,31]$. The action of low-level lasers is due to its biostimulatory effect it exert on various cells $[6$, 34]. Previous studies have reported that LLLT exert biologic effects on tissues in many ways such as stimulating
Springer Open (c) The Author(s). 2020 Open Access This article is licensed under a Creative Commons Attribution 4.0 International License, which permits use, sharing, adaptation, distribution and reproduction in any medium or format, as long as you give appropriate credit to the original author(s) and the source, provide a link to the Creative Commons licence, and indicate if changes were made. The images or other third party material in this article are included in the article's Creative Commons licence, unless indicated otherwise in a credit line to the material. If material is not included in the article's Creative Commons licence and your intended use is not permitted by statutory regulation or exceeds the permitted use, you will need to obtain permission directly from the copyright holder. To view a copy of this licence, visit http://creativecommons.org/licenses/by/4.0/. 
fibroblast maturation and motility that subsequently, enhance cell metabolism and proliferation [16, 23]

Previous studies observed that LLLT promotes fibroblast and keratinocyte cell locomotion [18, 42, 45, 46], collagen formation [26], growth factor production and angiogenesis [39] that result in enhancement of wound healing [4].

LLLT using laser devices such as helium-neon, diode, and gallium arsenide have been applied for different oral conditions. Treating mucositis [21], paresthaesia [17], and TMJ disorders [42] have been investigated. Furthermore, LLLT has been used for reducing post-operative discomfort after gingivectomy $[6,30]$, endodontic surgery [19], enhance healing, and dentinogenesis following pulpotomy [41] and as an adjunct to non-surgical periodontal therapy $[20,27,28]$.

The aim of the current study was to evaluate the effectiveness of LLLT on gingival healing following gingivectomy procedure.

\section{Subjects and methods}

\subsection{Study design and patient selection}

The study sample was selected from patients referred to the Department of Periodontology, Alexandria University, between September and December 2015. Inclusion criteria were systemic healthy patients aged from 22 to 45 years and diagnosed with chronic inflammatory gingival enlargement, non-pregnant and non-smoker. Gingivectomy procedure for maxillary or mandibular anterior region with at least six affected teeth was indicated.

Pre-surgical preparation for all subjects consisted of supra- and sub-gingival scaling, oral hygiene instructions and occlusal adjustments if needed. Initial probing depths were recorded for six sites for each affected tooth using William's probe (Hu-Friedy). After 4 weeks at reevaluation phase, the gingival condition of the patients was re-evaluated prior to the gingivectomy procedure.

\subsection{Ethical approvals}

The study protocol was approved by the internal review board of the Faculty of Dentistry, in accordance with the Declaration of Helsinki, and signed written consents were taken from the patients prior to the study.

\subsection{Surgical procedure}

Randomly, the patients were divided into two groups; the test group (10 patients, with mean age $37 \pm 2$ years) in which LLLT was applied after the gingivectomy. While in the control group (10 patients, with mean age $35 \pm 3$ years), no LLLT was used following the gingivectomy [16, 30] (Figs. 1 and 2).

The gingival pockets were first examined with a periodontal probe and marked with a pocket marker, then Kirkland knife was used for external bevel incision and Orban's knife was used for releasing the interdental tissue.

\subsection{Laser protocol}

After hemostasis, the surgical site of the test group was subjected to laser irradiation using diode laser (photon laser comp. $660 \mathrm{~nm}$ ) 50-mW output power, continuous wave, and beam diameter of $3 \mathrm{~mm}$ immediately after surgery and at days 3 and 5 p.s. The delivery tip was perpendicular to the gingival tissue surface at $1 \mathrm{~cm}$ distance
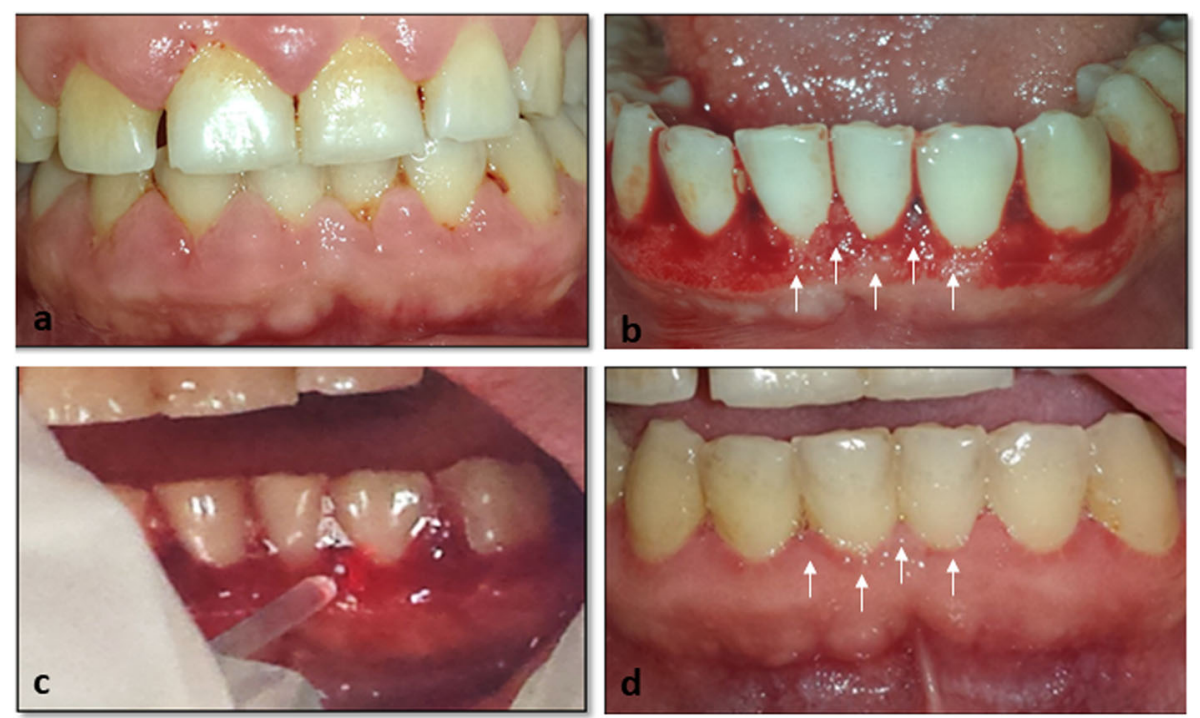

Fig. 1 Clinical view of gingival enlargement in mandibular incisors area indicated for gingivectomy (test group). a Before gingivectomy procedure. $\mathbf{b}$ Immediately after gingivectomy (white arrows). c Application of low-level laser therapy (LLLT) to the surgical site. $\mathbf{d}$ Gingival healing 2 weeks post-surgery. Note the change in gingival contour after surgery (white arrows in b) and 2 weeks later (swhite arrows in d) 

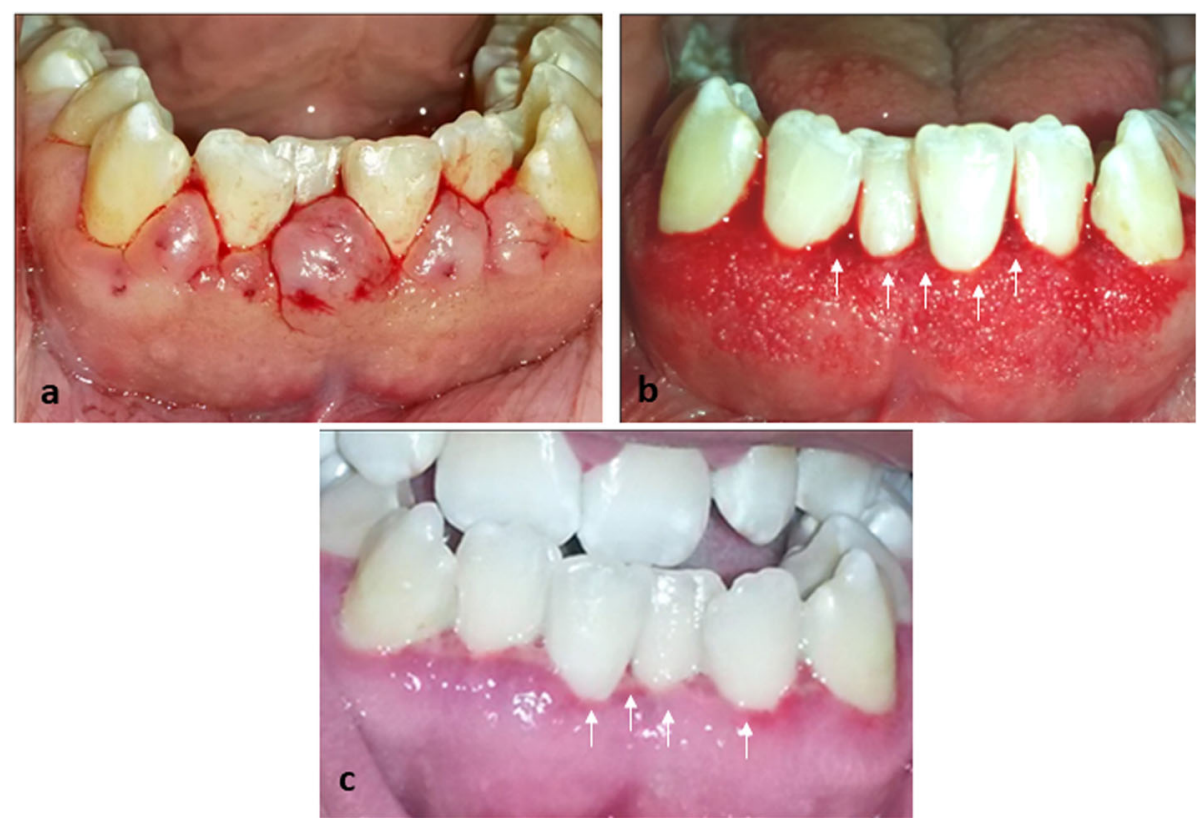

Fig. 2 Clinical view of gingival enlargement in mandibular incisors indicated for gingivectomy (control group). a Before gingivectomy procedure. b Immediately after gingivectomy. c Gingival healing 2 weeks post-surgery. Note the change in gingival contour after surgery (white arrows in $\mathbf{b}$ ) and 2 weeks later (white arrows in c)

in a scanning mode of an area about $1 \mathrm{~cm}^{2}$ for $80 \mathrm{~s}(4 \mathrm{~J} /$ $\mathrm{cm}^{2}$ energy density). Periodontal dressing (Coe-Pak) was applied on the surgical sites for both groups. A titanium foil was placed in the inner surface of the pack to prevent mechanical injury to the tissues during healing and during pack removal for further laser applications every $48 \mathrm{~h}$ for 1 week. In order to minimize inter-operator variations, the same periodontist (M.M) performed all surgical procedures.

\subsection{Clinical assessment}

Photographs of the surgical sites at pre-surgery, immediately post-surgery, and at $3,5,7$, and 14 days p.s. were taken. Two examiners assess the photographs to score three clinical parameters. These examiners were blinded to test and control pictures.

Clinical parameters consisted of tissue color (pink, red, bluish), tissue contour (normal, hyperplastic, atrophic), and clinical status of the healing wound for the specific time interval (normal, better than normal, worse than normal). A three-stage scale was used to assess the wound healing:

A) Healing score [19]

Score 0: control and laser-treated sites showed the same healing extent.

Score 1: better healing was observed for control than laser treated sites.

Score 2: better healing was observed for laser treated than control sites.

\section{B-Visual analogue scale scores (VAS) [14]}

The visual analogue scale is a continuous scale consists of a horizontal line of $10 \mathrm{~cm}$ in length with two endpoints. Score of 0 represents "no pain" while score 10 is for "worst pain." Patients recorded the severity of pain on the scale (0 no pain; $1-3$ slight pain; $4-6$ moderate pain; 7-10 severe pain) at four time points (immediately after treatment, 3,5 , and 7 days post-operatively).

\subsection{Statistical analysis}

Normality of data was evaluated using Shapiro-Wilk test. The nonparametric Mann-Whitney $U$ test was used to compare between laser and control groups regarding the healing score, while $t$ test was used for VAS score comparison. Significance was accepted at $p<0.05$. The nonparametric kappa test was used to evaluate agreement between the two examiners regarding the healing score.

\section{Results}

\subsection{Clinical results}

\subsubsection{Healing score}

Both groups showed similar results immediately postsurgery. At day 3 p.s., a better improvement was observed in wound healing for laser than control group. Significant improved healing for laser than control group was detected at 5,7 , and 14 days p.s. Significant difference was observed between day 1 and $5(z=-2.6, p=$ 0.009), $7(z=-2.98, p=0.002)$, and $14(z=-2.9, p=$ 


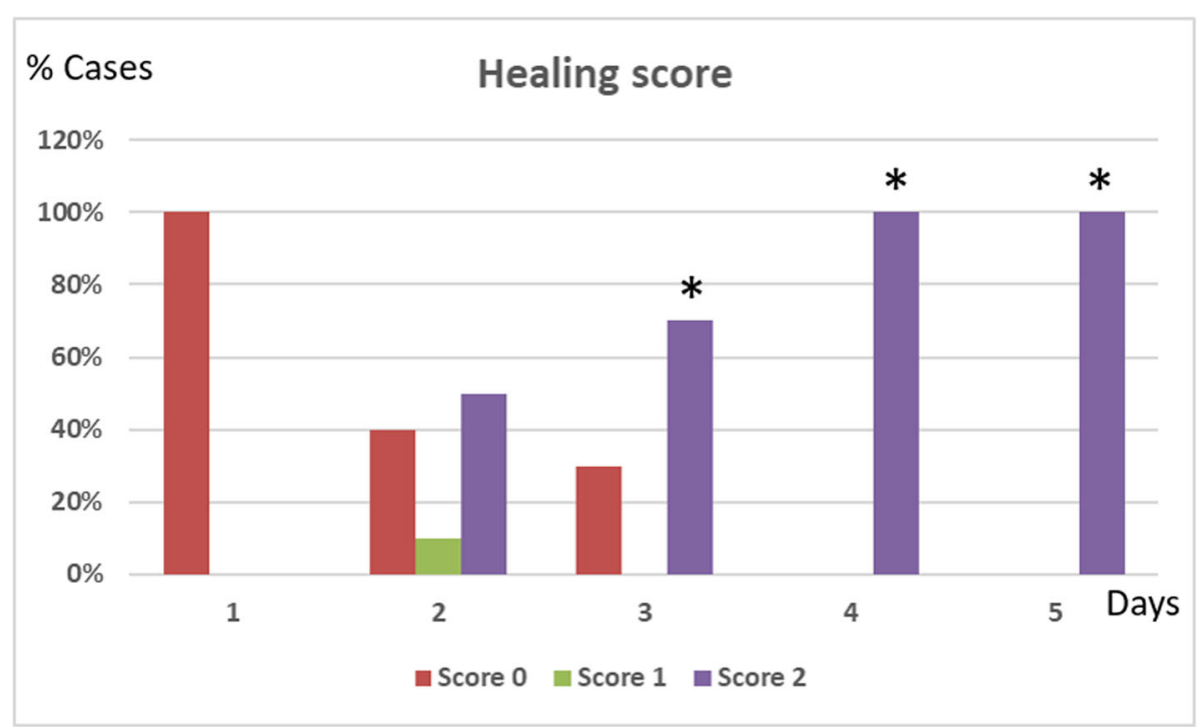

Fig. 3 Graphical presentation of gingival wound healing for laser (test) and control groups during the study period. At day 1, all cases showed same healing (score 0). Starting from day 3, better healing was observed in laser than control group (score 2). Score 0: control and laser-treated sites showed the same healing extent. Score 1: better healing was observed for control than laser treated sites. Score 2: better healing was observed for laser treated than control sites. (* significant difference, $p<0.05)$

0.002) (Fig. 3). The kappa index of scoring agreement between the examiners was 0.671 .

\subsubsection{VAS}

Both groups showed similar results at day $1(\mathrm{t} 1=$ $0.80178, p$ value $=0.211$ ). At day 3,5 , and 7 p.s., a significant reduction in VAS score was shown for laser compared to the control group ( $\mathrm{t} 3=-4.9, p=0.0004$, $\mathrm{t} 5=-6.1 p=0.0001, \mathrm{t} 7=-2.05, p=0.027)($ Table 1$)$.

\section{Discussion}

The perceptions of patients' desire regarding painless minimally invasive treatment have gained LLLT a lot of interest in field of dentistry [25]. Previous studies described the application of LLLT for management of oral and periodontal conditions [1-4].

Previous studies showed that low-level laser therapy (LLLT) regulates many cellular functions, increase ATP synthesis, and enhances the healing activity $[15,34]$.

Different LLLT parameters have been used to assess its influence on wound healing. Laser has shown effectiveness in modulating cellular events in vitro that leads to accelerated healing process. However, no consensus on specific laser parameter was reached [32].

Our findings showed that LLLT positively enhance wound healing following the gingivectomy procedure as well as decrease the post-operative pain perception by patients. This is in agreement with Oncu et al. [24]; they showed that diode laser significantly accelerate healing and decrease patients' discomfort following gingivectomy.

In this study, the selected parameters were $4 \mathrm{~J} / \mathrm{cm} 2$ and exposure time of $80 \mathrm{~s}$ that were applied immediately following surgery and repeated on alternative days for 1 week. These parameters have been previously investigated and showed favorable results [32].

Our findings are in contrast to Damante et al. [6] in which they showed that LLLT did not improve healing following gingivoplasty. This could be due to the different laser settings that were used than in our study. Damante et al. [6] used single application of $15 \mathrm{~mW}$ GaAlAs laser in a punctual mode on the right side of 16

Table 1 Visual analogue scale scores (VAS) for laser and control groups during the study period

\begin{tabular}{lllll}
\hline Days & 1 & 3 & 5 & 7 \\
\hline Test $($ mean \pm SD) & $4 \pm 0.63$ & $2.7 \pm 0.64$ & $1.9 \pm 0.32$ & $0.1 \pm 0.3$ \\
Control (mean \pm SD) & $4.2 \pm 0.41$ & $4 \pm 0.43$ & $3 \pm 0.43$ & $0.5 \pm 0.53$ \\
$t$ value & $\mathrm{t} 1=-0.80178$ & $\mathrm{t} 3=-4.9$ & $\mathrm{t} 5=-6.1$ & $\mathrm{t}=-2.05$ \\
$p$ value & 0.211 & $0.0004^{*}$ & $0.0001^{*}$ & $0.027^{*}$ \\
\hline
\end{tabular}

A statistically significant reduction in VAS score in the laser compared to the control group at days 3, 5, and 7 p.s. Significant reduction in VAS score was shown between laser and control group at 3, 5, and 7 days post-operatively

*Significant difference, $p<0.05$ 
patients while in our study a $50-\mathrm{mW}$ GaAlAs laser was applied in scanning mode over the wound area every $48 \mathrm{~h}$ for 1 week.

Previous studies [36, 39] showed that production of fibroblast growth factors by macrophages and fibroblasts was boosted following LLLT application. It has been suggested that LLLT application improved wound healing through increasing keratinocytes' proliferation, stimulating early epithelization and improving neovascularization. Following gingivectomy, collagen production and organized tissue alignment occur gradually within 3-4 weeks [29]. Thus, acceleration of the wound healing process with laser can be interpreted by a greater collagen production and vascular proliferation in the connective tissue combined with higher proliferative activity in epithelial cells

LLLT has been found to promote growth factors release in the blood stream, which can reach adjacent and distant sites of the body [6]. Therefore, it can be speculated that the application of laser to one site in the mouth may affect the adjacent site as well. In order to avoid this systemic effect of laser therapy we used casecontrol individuals in the current study and not split mouth design .

The mechanisms by which LLLT acts are complex but mainly depends on the stimulation of normal cell functions that is induced by low levels of laser energy. This result is due to modifying the mitochondrial respiratory chain or the calcium channels $[13,33]$ which consequently stimulates cell proliferation and metabolism [16]. Enhancement of cell proliferation and decreasing the levels of inflammatory cytokines, the healing of the oral mucosa would be accelerated [2]. Previous studies demonstrate the ability of LLLT in stimulating human fibroblasts, immune cells, and epithelial cells along with enhanced angiogenesis, growth factor release, and decreasing post-operative pain which ultimately leads to improved wound healing [12, 27].

The laser group showed significant better healing score than the control group at 5, 7, and 14 days p.s. This could be due to the increase in revascularization that accelerate healing following LLLT [8].

In the current study, the highest VAS reduction percentage was observed in laser group. This comes in agreement with Reddy et al. [30] who noted a significant decrease in pain score for the laser group especially in the first 2 days following surgery compared to conventional treatment. Also, Enwemeka et al. [9] in their meta-analysis concluded that laser phototherapy may be considered a highly efficient therapeutic approach for pain relief and tissue repair. Silveira et al. [34] suggested that low-level laser application increase ATP production that hasten the healing process of muscles.

Our finding agrees with previous reports $[1,7,11]$ in which they noticed that $75 \%$ of patients suffering from recurrent apthous ulcer RAS recorded reduced pain perception immediately following laser application than those who used topical steroids.

Similarly, Hersheal et al. [11] found faster healing and reduced pain after using laser application on RAS. They concluded that LLLT represent the most beneficial treatment for minor RAS. However, longitudinal clinical trials are further recommended to explore the advantages of LLLT in treatment of various oral conditions.

\section{Conclusion}

Low-level laser as an adjunctive therapy to gingivectomy procedure can be used to decrease patients' pain perception following surgery and accelerate the healing process especially in the early phases.

\section{Abbreviations}

LLLT: Low-level laser therapy; VAS: Visual analogue scale; GaAIAs: Gallium aluminum arsenide; RAS: Recurrent apthous ulcer

\section{Acknowledgements}

Not applicable

Authors' contributions

M M: carried out the clinical part. MM and M M M carried out the manuscript writing and results analysis. All authors have read and approved the manuscript.

\section{Funding}

No funding to be reported in this study.

Availability of data and materials

Data is available upon request from authors.

Ethics approval and consent to participate

The protocol of the study was approved by the internal review board (IRB no.: 00010555) of the Faculty of Dentistry, Alexandria University, in accordance with the Declaration of Helsinki, and signed written consents were taken from the patients prior to the study.

Consent for publication

The consent of authors was taken before submission.

Competing interests

The authors declare that they have no competing interests.

\section{Author details}

${ }^{1}$ Preventive Dental Sciences Department, Periodontology Division, Imam Abdulrahman Bin Faisal University, Dammam, Saudi Arabia. ${ }^{2}$ Biomedical Dental Sciences Department, Oral Medicine Division, Imam Abdulrahman Bin Faisal University, Dammam 31441, Saudi Arabia.

Received: 27 January 2020 Accepted: 29 April 2020

Published online: 01 July 2020

\section{References}

1. Albrektson M, Hedström L, Bergh H (2014) Recurrent aphthous stomatitis and pain management with low-level laser therapy: a randomized controlled trial. Oral Surg Oral Med Oral Pathol Oral Radiol Endod. 117(5): 590-594

2. AlGhamdi KM, Kumar A, Moussa NA (2012) Low-level laser therapy: a useful technique for enhancing the proliferation of various cultured cells. Lasers Med Sci 27:237-249

3. Aoki A, Takasaki A, Nagai S, Yoshida I, Zeredo JL, Mizutani K et al (2008) Current status of clinical laser applications in periodontal therapy. Gen Dent. 56(7):674-687 
4. Arany PR, Nayak RS, Hallikerimath S, Limaye AM, Kale AD, Kondaiah P (2007) Activation of latent TGF- $\beta 1$ by low-power laser in vitro correlates with increased TGF- $\beta 1$ levels in laser-enhanced oral wound healing. Wound Repair Regen. 15(6):866-874

5. Chawla K, Lamba AK, Tandon S, Faraz F, Gaba V (2016) Effect of low-level laser therapy on wound healing after depigmentation procedure: a clinical study. J Indian Soc Periodontol. 20:184-188

6. Damante CA, Greghi SLA, Sant'anna ACP, Passanezi E, Taga R (2004) Histomorphometric study of the healing of human oral mucosa after gingivoplasty and low-level laser therapy. Lasers Surg Med. 35:377-384

7. De Souza T, Martins MA, Bussadori SK, Fernandes KP, Tanji EY, MesquitaFerrari RA et al (2010) Clinical evaluation of low-level laser treatment for recurring aphthous stomatitis. Photomed Laser Surg. 28(2):85-88

8. Donos N, D'Aiuto F, Retzepi M, Tonetti M (2005) Evaluation of gingival blood flow by the use of laser Doppler flowmetry following periodontal surgery. A pilot study. J Periodontal Res. 40:129-137

9. Enwemeka CS, Parker JC, Dowdy DS, Harkness EE, Harkness LE, Woodruff D (2004) The Efficacy of Low-Power Lasers in Tissue Repair and Pain Control: A Meta-Analysis Study. Photomed Laser Surg. 22(4):323-329

10. Fujiyama K, Deguchi T, Murakami T, Fuji A, Kushima K, Takano-Yamamoto T (2008) Clinical effect of CO2 laser in reducing pain in orthodontics. Angle Orthod. 78(2):299-203

11. Hersheal A, Mohit PS, Prashant N, Hemant M, Sowmya GV (2014) Efficacy of low-level laser therapy in treatment of recurrent aphthous ulcers-a sham controlled, split mouth follow up study. J Clin Diagn Res. 8(2):218-221

12. Hopkins JT, McLoda TA, Seegmiller JG, David BG (2004) Low-level laser therapy facilitates superficial wound healing in humans: A Triple-blind, sham-controlled study. J Athl Train. 39:223-229

13. Huang $Y Y$, Chen AC, Carroll JD, Hamblin MR (2009) Biphasic dose response in low level light therapy. Dose Response. 7:358-383

14. Huskisson EC, Scott JJ (1976) Application of visual-analogue scales to the measurement of functional capacity. Rheumatol Rehabil. 15:185-187

15. Karu T (2010) Mitochondrial Mechanisms of Photobiomodulation in Context of New Data About Multiple Roles of ATP. Photomed Laser Surg. 28(2):159-160

16. Khadra MK, Lyngstadaas N, Haanaes SP, Mustafa K (2005) Laser therapy accelerates initial attachment and subsequent behavior of human oral fibroblasts cultured on titanium implant material. A scanning electron microscope and histomorphometric analysis. Clin Oral Implants Res. 16:168-175

17. Khullar S, Emami B, Westermark A, Haanaes HR (1996) Effect of low-level laser treatment on neurosensory deficits subsequent to sagittal split ramus osteotomy. Oral Surg Oral Med Oral Pathol Oral Radiol Endod. 82:132-138

18. Kreisler M, Christoffers AB, Willerstausen B, d'Hoedt B (2003) Effect of lowlevel GaAIAS laser irradiation on the proliferation rate of human periodontal ligament fibroblasts an in vitro study. J Clin Periodontol. 30:353-358

19. Kreisler MB, Haj HA, Noroozi N, Willershausen B (2004) Efficacy of low level laser therapy in reducing postoperative pain after endodontic surgery - a randomized double blind clinical study. Int J Oral Maxillofac Surg. 33:38-41

20. Kreisler M, Al Haj H, d'Hoedt B (2005) Clinical efficacy of semiconductor laser application as an adjunct to conventional scaling and root planing. Lasers Surg Med. 37:350-355

21. Lara RN, Da Guerra EN, De Mola NS (2007) Macroscopic and microscopic effects of GaAlAs diode laser and dexamethasone therapies on oral mucositis induced by fluorouracil in rats. Oral Hlth Prev Dent. 5:63-71

22. Nevins M, Nevins ML, Parma-Benfenati S, Benfenati MR, Schupbach P, Chen CY et al (2020) Human Clinical and Histologic Evaluations of Laser-Assisted Periodontal Therapy with a 9.3- $\mu \mathrm{m}$ CO2 Laser System. Int J Periodontics Restorative Dent. 40(2):203-210

23. Noble PB, Shields ED, Blecher PD, Bentley KC (1992) Locomotory characteristics of fibroblasts within a three-dimensional collagen lattice: Modulation by a helium/neon soft laser. Lasers Surg Med. 12(6):669-674

24. Öncü E, Erbeyoğlu AA, Alan R (2017) Comparison of gingivectomy procedures for patient satisfaction: conventional and diode laser surgery. Selcuk Dent J. 4:6-9

25. Ozcelik O, Haytac MC, Kunin A, Seydaoglu G (2008) Improved wound healing by low-level laser irradiation after gingivectomy operations: a controlled clinical pilot study. J Clin Periodontol 35:250-254

26. Pinheiro AL, Pozza DH, Oliviera MG, Weissmann R, Ramalho LM (2005) Polarized light (400-2000 nm) and nonablative laser (685 nm): a description of the wound healing process using immunohistochemical analysis. Photomed Laser Surg. 23:485-492
27. Posten W, Wrone DA, Dover JS, Arndt KA, Silapunt S, Alam M et al (2005) Low-level laser therapy for wound healing: Mechanism and efficacy. Dermatol Surg. 31:334-340

28. Qadri T, Miranda L, Tuner J, Gustafsson A (2005) The short-term effects of low-level lasers as adjunct therapy in the treatment of periodontal inflammation. J Clin Periodontol 32:714-719 27-9

29. Ramfjord SP, Ash MM Jr (1991) Periodontologia e Periodontia: Teoria e Prática Moderna [in Spanish]. Santos, São Paulo

30. Reddy SP, Koduganti RR, Panthula VR, Prasanna JS, Gireddy H, Dasari R et al (2019) Efficacy of low-level laser therapy, hyaluronic acid gel, and herbal gel as adjunctive tools in gingivectomy wound healing: a randomized comparative clinical and histological study. Cureus. 11(12):e6438

31. Sanz-Moliner JD, Nart J, Cohen RE, Ciancio SG (2013) The effect of an 810$\mathrm{nm}$ diode laser on postoperative pain and tissue response after modified widman flap surgery: a pilot study in humans. J Periodontol. 84:152-158

32. Schindl A, Schindl M, Schön H (2000) Low-intensity laser therapy: a review. J Invest Med 48:312-326

33. Silveira PC, Streck EL, Pinho RA (2007) Evaluation of mitochondrial respiratory chain activity in wound healing by low-level laser therapy. J Photochem Photobiol B. 86:279-282

34. Silveira PCL, Acordi da Silvaa L, Fragab DB, Freitasb TP, Streckb EL, Pinhoa $R$ (2009) Evaluation of mitochondrial respiratory chain activity in muscle healing by low-level laser therapy. J Photoch Photobio B 95(2,4):89-92

35. Schwarz F, Aoki A, Becker J (2008) Sculean. Laser application in non-surgical periodontal therapy: a systematic review. J Clin Periodontol. 35:29-44

36. Steinlechner CWB, Dyson M (1993) The effects of Low Level Laser therapy on the proliferation of keratinocytes. Laser Therapy. 5(2):65-73

37. Slot DE, Kranendonk AA, Paraskevas S, Van der Weijden F (2009) The effect of a pulsed Nd: YAG laser in non-surgical periodontal therapy. J Periodontol. 80(7):1041-1056

38. Stubinger S (2010) Advances in bone surgery:the Er:YAG laser in oral surgery and implant dentistry. Clin Cosmet Investig Dent. 2:47-62

39. Tuby H, Maltz L, Oron U (2006) Modulations of VEGF and iNOS in the rat heart by low level laser therapy are associated with cardioprotection and enhanced angiogenesis. Lasers Surg Med. 38:682-688

40. Turhani D, Scheriau M, Kapral D, Benesch T, Jonke E, Bantleon HP (2006) Pain relief by single low-level laser irradiation in orthodontic patients undergoing fixed appliance therapy. Am J Orthod Dentofac Orthop. 130: 371-377

41. Uloopi KS, Vinay C, Ratnaditya A, Satya Gopal A, Mrudula KJN, Chandrasekhar RR (2016 Jan) Clinical Evaluation of Low Level Diode Laser Application For Primary Teeth Pulpotomy. J Clin Diagn Res. 10(1):ZC67-ZC70

42. Venancio RA, Camparis CM, Lizarelli RF (2005) Low intensity laser therapy in the treatment of temporomandibular disorders: a double-blind study. J Oral Rehabil. 32:800-807

43. Walsh LJ (1997) The current status of low level laser therapy in dentistry. Part 1. Soft tissue applications. Aust Dent J. 42:247-254

44. Walsh LJ (2003) The current status of laser applications in dentistry. Aust Dent J. 48(3):146-155

45. Yadwad KJ, Veena HR, Sudhir RP, Shivaprasad BM (2017) Diode laser therapy in the management of chronic periodontitis - A clinico-microbiological study. Interv Med Appl Sci. 9(4):191-198

46. Yu HS, Chang KL, Yu CL, Chen JW, Chen GS (1996) Low-energy heliumneon laser irradiation stimulates interleukin-1 alpha and interleukin-8 release from cultured human keratinocytes. J Investig Dermatol. 107:593-596

\section{Publisher's Note}

Springer Nature remains neutral with regard to jurisdictional claims in published maps and institutional affiliations. 